\section{Understanding Motivations for Gardening Using a Qualitative General Inductive Approach}

\author{
Amy McFarland ${ }^{1,5}$, Tina M. Waliczek ${ }^{2,6}$, Coleman Etheredge ${ }^{3,5}$, \\ and Aime J. Sommerfeld Lillard ${ }^{4,7}$
}

ADDITIONAL INDEX WORDS. human issues in horticulture, intergenerational gardening, food systems, food movement, community gardens, horticultural therapy

SUMMARY. Although some benefits of gardening have been documented, motivations regarding participation in gardening are often considered based on anecdote. The purpose of this study was to use qualitative analysis to explore reasons gardeners from different genders and generations participate in gardening. The questions developed for this study were intentionally exploratory and left openended to gather a large variety of responses. Surveys were collected from 177 individuals between the ages of 7 and 94 years old. Responses were categorized into themes identified through the literature review, the pilot study, and through exploration of the data. Responses could fit into as many categories as were mentioned by the respondents and were categorized by three independent coders. Interrater reliability was assessed using a two-way mixed, absolute agreement, average measures intraclass correlation (ICC) and determined the degree to which coders provided consistency in their ratings across participants. Themes developed through this survey included "social interaction," "aesthetics," "food availability/ health/nutrition," "economics," "therapeutic," "environmental benefits," "nostalgia," and "personal productivity." Themes of personal productivity and nostalgia are those which have not occurred in previous research. Statistically significant differences were found in comparisons among males and females with more males gardening for food/health/nutrition and for reasons regarding nostalgia. More females reported gardening for personal productivity when compared with males. No significant difference was identified in comparisons of gardeners from various age groups indicating that gardeners across generations have similar intentions and receive similar benefits.

G ardening is one of the most popular home-based leisure activities in the United States (Ashton-Shaeffer and Constant, 2005). Gardening offers a fascinating experience as an activity with a degree of universality that transcends differing backgrounds through contact with nature and a first-hand viewing of the cycle of life (Kaplan, 1973). The whole family can participate in gardening (Carney et al., 2012), including special populations, such as older adults and people with disabilities (Relf and Dorn,

${ }^{1}$ Food and Agricultural Studies, Frederik Meijer Honors College, Grand Valley State University, Allendale, MI 49401

${ }^{2}$ Department of Agriculture and Horticulture, Texas State University, San Marcos, TX 78666

${ }^{3}$ Department of Plant and Soil Sciences, Mississippi State University, Starkville, MS 39759

${ }^{4}$ Baylor University, Waco, TX 76705

${ }^{5}$ Assistant Professor

${ }^{6}$ Professor

${ }^{7}$ Continuing Education Instructor

${ }^{9}$ Corresponding author. E-mail: tcl0@txstate.edu.

https://doi.org/10.21273/HORTTECH03972-18
1995). Gardening is the second most common leisure activity of adults older than 65 years (Yusuf et al., 1996), and they may choose to garden for many reasons, including physical health and exercise, mental health, recreation, creativity, intellectual expansion, friendship, produce quality and nutrition, self-expression/self-fulfillment, cost and convenience, and spiritual reasons (including contact with nature) (AshtonShaeffer and Constant, 2005; Blair et al., 1991). According to Bhatti (2006), "There is usually creative, financial, physical, and emotional investment in the garden; it becomes a salient feature in people's lives." Similarly, children often garden for exploration, learning, and play (Koch et al., 2006; Pigg et al., 2006).
Gardening can have a number of benefits to participants, including increasing physical activity levels, improving consumption habits of those who participate, and improving mental facilities. Fruit and vegetable consumption may be increased because of experiences with gardening (Devine et al., 1999; Koch et al., 2006; Sommerfeld et al., 2010), resulting in healthier diets which can have dramatic effects on reducing a person's risk for many chronic diseases (Blanchard et al., 2004; Centers for Disease Control and Prevention, 2007; Park et al., 2011). Gardeners also frequently report that gardening keeps them mentally and physically active (Infantino, 2004). Gardening has a significant influence on positive lifetime attitudes and habits, including successful and healthy aging, resiliency, hardiness, adaptability, creativity, self-transcendence, and a positive outlook on life (Infantino, 2004). Similar results were reported in research conducted with gardeners and the effect gardening had on their quality of life (Boyer et al., 2002; Waliczek et al., 2005).

Understanding why people engage in gardening throughout a lifetime and as a hobby may be helpful in developing programs that can help improve health and overall quality of life to meet needs of target populations. Research and anecdotal evidence showed some general motivations of all gardeners to include improving environmental quality, experiencing relaxation and recreation, supporting psychospiritual benefits, growing for nutrition and food, establishing cultural identity, increasing social interaction, and improving economics (Mast, 2013). Knowing gardener motivations can also help the horticulture industry market and supply horticultural products to target populations. According to Behe et al. (2010), understanding market segments of gardeners is critically important to marketing strategies.

The purpose of this study was to use qualitative analysis to explore reasons gardeners from different

\begin{tabular}{llll}
\hline $\begin{array}{l}\text { Units } \\
\text { To convert U.S. to SI, } \\
\text { multiply by }\end{array}$ & U.S. unit & SI unit & $\begin{array}{l}\text { To convert SI to U.S., } \\
\text { multiply by }\end{array}$ \\
\hline 0.0929 & $\mathrm{ft}^{2}$ & $\mathrm{~m}^{2}$ & 10.7639 \\
0.4536 & $\mathrm{lb}$ & $\mathrm{kg}$ & 2.2046
\end{tabular}


genders and generations participate in gardening.

\section{Materials and methods}

Qualitative studies are known for producing more diverse findings which are sometimes overlooked using quantitative approaches (Blair, 2009). Therefore, this study used a general inductive approach (Thomas, 2006) to gain insights into motivations for participating in gardening activities by summarizing, classifying, and organizing data drawn from participants.

InSTRUMENTATION. The questions developed for this study were intentionally exploratory and left open-ended to gather a large variety of responses. Questions were reviewed for validity by a panel of qualitative and horticultural researchers experienced in survey construction and administration. The survey asked respondents if and why they gardened, what it meant to them to be a gardener, what their first memory related to gardening was, and if they could explain any specific feelings they had associated with gardening. No definition of "gardener" was included to allow self-identification and inclusion of a variety of forms of gardening. Demographic information was also collected and included age, gender, location of birth, and current living location.

Pilot study. A pilot study was conducted to test the open-ended motivations for gardening instrument for readability with gardeners of different ages, demographics, and levels of gardening experience. The seven convenience-elected participants included in the pilot study ranged in age from 7 to 80 years and were included to have respondents from multiple generations. Questions were found to be suitable in gleaning information from all age and demographic groups. Initial themes of "garden characteristics" such as gardening for aesthetics and food, "people" such as gardening for family involvement, and experiences such as gardening for "learning" were identified through this pilot test.

SAMPLE. Because the questions were found suitable for a wide range of respondents with varied demographics, the study was expanded to collect information from a larger sample and geographic region. The target sample for this study was any individual who indicated they participated in gardening activities. "Paper/pencil" format surveys were distributed to garden, church, and social and community service groups within Kansas, Texas, Washington, D.C., and parts of the mideastern United States. A convenience sample was selected based on accessibility by researchers, interest level, and willingness to participate. A packet of flower or vegetable seed was given as an incentive for participation and a token of appreciation. Surveys were administered by researchers or distributed by a group director and took most respondents less than 15 min to complete.

DATA COLLECTION AND ANALYSIS. Responses were categorized by three independent coders into themes identified through the literature review, the pilot study, and through exploration of the data. Text from responses was coded as a unit where responses could fit into as many categories as were mentioned. Interrater reliability was assessed using a twoway mixed, absolute agreement, average measures ICC to assess the degree of consistency in coders' ratings across participants (Shrout and Fleiss, 1979). The $\operatorname{ICC}(3,3)$ was 0.860 , which is in excellent agreement (Cicchetti, 1994). In any rating where coders did not agree, the ratings of two of the three coders in agreement were used for data analysis.

After responses were coded, data were entered into IBM SPSS Statistics (version 20; IBM Corp., Armonk, $\mathrm{NY}$ ) and SAS (version 9.4; SAS Institute, Cary, NC). Descriptive statistics including frequencies were calculated to understand the demographic breakdown of the sample and to discern the degree to which participants mentioned each theme as a particular reason for gardening. Participants were broken into age groups following previous research related to gardening groups (Hale et al., 2011).

Pearson's chi-square was used to evaluate the differences between the responses of males compared with females and linear regression was used to compare the responses of participants in different age groups. To compare age groups using linear regression, dummy binary variables were created for each of the five age groups identified. Fisher's exact test significance reported in cases where a cell had fewer than five samples. The alpha level for statistical significance was set at 0.10 . This level of significance is considered conventional in social sciences and with smaller data sets (Kelley et al., 2017; Noymer, 2008).

\section{Results and discussion Descriptive statistics}

Surveys were collected from 177 individuals. Frequency statistics were calculated for demographic responses to describe the sample group. The sample group consisted of 50 men $(28.2 \%), 126$ females $(71.2 \%)$, and 1 respondent $(0.6 \%)$ who did not provide their gender. Past research has identified similar unequal representation between male and female respondents in gardening research (Hawkins et al., 2012); however, the National Gardening Association's national survey of gardening activities results in near equal representation (B. Butterfield, personal communication), indicating that this discrepancy is not necessarily representative of the overall horticultural market.

The sample group consisted of respondents between the ages of 7 and 94 years. The mean age was $\mathbf{5 2 . 8}$ years $(\mathrm{SD}=18.3)$. The participants were classified according to age group with $52 \%$ representing the largest group, adults older than 55 years. One percent $(2)$ of them were younger than 18 years, $22 \%(40)$ were 18 34 years, almost $7 \%$ (12) were $35-44$ years old, nearly $12 \%(21)$ were $45-$ 54 years, and $5.6 \%(10)$ did not share their age. This age group representation appears to be similar to other horticultural market research that shows most horticultural consumers tend to be in the older than 55 years age group (Butterfield, 2009; Hawkins et al., 2012). It is likely that the smaller response rate of participants younger than 18 years reflects the lack of access to the survey through list serves or another older member of the household completing the survey.

\section{Themes developed}

Therapeutic. With 92\% (163) of gardeners responding in the therapeutic theme category, the results indicated that the primary reason gardeners in this study reported garden participation was for unseen benefits, something that spoke to their soul, relaxation, or a therapeutic way 
to be in touch with nature (Table 1 ). The therapeutic theme was documented through statements such as, "gardening makes me feel alive and gets me back in touch with the earth" and "I like to garden because it is very therapeutic for me." A respondent with a medical condition reported how important it was to be able to participate in and see the circle of life. These statements indicated that the participants valued gardening for reasons related to their mental wellbeing. This supported results from other research such as that participation in gardening can enhance mental health (Kaplan, 1992; Kidd and Brascamp, 2004), reduce stress (Kelley et al., 2017), improve perceptions of self-esteem and quality of life (Waliczek et al., 1996), and produce physiological impacts such as lower blood pressure and reduced muscle tension (Relf, 1998).

Food availability/health/ NUTRITION. This theme is a combination of respondents' reflections related to their accessibility to fresh food, health and nutritional benefits of fruits and vegetables, and concern regarding the healthfulness of inputs involved during food production. With nearly $42 \%$ (74) of gardeners responding in this category, respondents' references to fresh fruit and vegetables was especially notable (Table 1). Within this theme, gardeners reflected that fruit and vegetables are important components of a healthy diet, providing many essential vitamins and minerals. Not only did respondents recognize the health also the effect of the management practices and growing conditions of their plants in relation to their own health. For example, some respondents were concerned with the effect of chemical pesticides or genetically benefits of fruit and vegetables but

modified crops impacting their health or their family's health.

Finally, this theme included notations that conveyed positive associations between physical activity and gardening. The food, nutrition, and health theme was documented through statements such as, "for food for which I know all of the inputs," "I also like that it is fresh produce and healthier," and "I get exercise and enjoyment from digging, planting, planning, harvesting and eating." Studies support this finding because people who garden have better nutritional attitudes and consume more fruit and vegetables when compared with those who do not garden (Koch et al., 2006; Sommerfeld et al., 2010).

Aesthetics. Results of this study documented respondents gardening for the aesthetic value [28\% (50)] (Table 1). An interesting difference in perceptions of gardens was found between the youngest and oldest respondent; to the youngest respondent, a garden must have flowers, to the oldest respondent, flowers were flowers and gardens were food. The aesthetics theme was documented through statements such as, "providing beauty to my house" and "to create inviting spaces to linger." These statements reflected the value of gardening for beauty and visual enjoyment. Past studies have found that gardening helped gardeners meet higher order needs on Maslow's hierarchy of human needs including those relating to self-actualization with community gardeners stating that they enjoyed creating beauty (Waliczek et al., 1996).

Economics. Some participants listed economic incentives as reasons for gardening [21.5\% (38)] (Table 1). This theme included descriptions of benefits previously reported in research such as seeing reduced grocery

Table 1. Frequency of responses for reasons for gardening by theme in the study of understanding motivations for gardening.

\begin{tabular}{lcc}
\hline Theme & Respondents (no.) & Respondents (\%) \\
\hline Therapeutic & 163 & 92.1 \\
Food/health/nutrition & 74 & 41.8 \\
Aesthetics & 50 & 28.2 \\
Economics & 38 & 21.5 \\
Social interactions & 31 & 17.5 \\
Personal productivity & 24 & 13.6 \\
Environmental benefits & 12 & 6.8 \\
Nostalgia & 7 & 4.0 \\
\hline
\end{tabular}

bills, saving money, and obtaining self-sufficiency and differed from the food availability, nutrition, and health theme in that participants used specific verbiage related to economics. Reduced food access and food security for families has been linked to economic factors such as rising fuel costs (Webber and Rojhani, 2010) and is a current problem in the United States (Carney et al., 2012). The economic theme was documented through statements such as, "it saves my family money" and "it saves me a lot of money not having to buy it at the store." One recent study estimated the value of urban backyard gardens and found that overall garden products were valued at $\$ 2 / \mathrm{lb}$ if purchased in a grocery store and that each square foot of garden space produced $\approx 1 \mathrm{lb}$ of produce (CoDyre et al., 2015).

Social InTERACTIONs. This study demonstrated that gardens can be used as locations to share experiences and bounty with others as well as to develop stories and memories. With $17.5 \%$ (31) (Table 1) of respondents reporting statements related to social interaction, analysis of interviews highlighted the importance of interactions in the garden with families and friends. Also noteworthy was the wide age range of participants (7-94 years old) identifying that the benefits are derived among various generations and within families. This finding is similar to those of Waliczek et al. (1996) who reported that gardening is sometimes used as a means of connecting with children in a common intergenerational activity. Social interaction was documented through statements such as, "to spend time with my mom" and "I used to help my grandma out, so she got me started." Other research has shown the importance of social interaction in terms of overall well-being. Everard et al. (2000) found that, in general, older adults engaged in activities associated with social engagement considered those activities more positively with respect to their overall well-being when compared with engaging in activities related to just passing time.

Personal productivity. More than $13 \%$ (24) of respondents wrote statements about increased personal productivity (Table 1 ). This theme 
included concepts related to learning while observing, exploring, and the avoidance of wasting time. Like the therapeutic theme, participants who identified with this premise found gardening valuable for sometimes intangible benefits. The personal productivity theme was identified through statements such as, "to be a gardener means to explore and learn about the world directly outside your front door" and "to be able to provide for myself and others through knowledge." Although gardens have historically been used for teaching and learning (Gutek, 2004; Pigg et al., 2006), this particular theme regarding reducing idleness has not been previously directly mentioned in the literature.

ENVIRONMENTAL BENEFITS. Nearly $7 \%$ (12) of respondents mentioned environmental benefits in their answers to survey questions regarding motivations of gardening (Table 1 ). The environmental benefits theme was documented through statements such as, "mostly to grow organic" and "to be a good steward of the environment." These statements indicated that participants valued their contribution to maintaining and improving the environment through gardening practices. Gardens have traditionally and historically been a tool used to teach environmental stewardship (Aguilar et al., 2008). Horticultural marketing is particularly interested in understanding consumers' ecopractices as a way to increase perceived value of products. Understanding gardeners' perceptions of the environmental benefits associated with gardening and the frequency with which gardeners associate gardening with the environment could provide critical feedback to this expanding marketing area (Behe et al., 2010, 2013).

Nostalgia. Four percent (7) of gardeners participated in gardening as a means of tradition, remembrance, or a connection to the past (Table 1). This theme represented instances where participants reflected positively on memories associated with gardening. People, places, or events could all be included in memories of the past. This theme was documented through statements such as, "carrying on a tradition great grandma, grandma and my mother all enjoyed and took pride in their flower gardens and veg gardens" and "gardening with my grandmother and grandfather's giant rose bush that he talked to and fed whiskey to each and every day for 40 years." These statements indicated that participants valued gardening because of memories and connections to their past. This motivation has not been documented previously in the literature.

FreQUeNCY OF THEMES. Whereas some participants' responses were represented within only one theme $[33.3 \%(59)]$, two or more themes were identified by $64.9 \%$ (118) of participants (Table 2). Although no participants identified with all themes, three $(1.7 \%)$ participants had representation in six of the eight themes and another three (1.7\%) had responses that could not be classified within the themes identified. One response that did not fit into the identified themes revolved around the practice of gardening reflecting the respondent's professional work. Another respondent mentioned that gardening was,

Table 2. Frequency of number of themes represented in the study of understanding motivations for gardening.

\begin{tabular}{lcc}
\hline Theme frequency & Respondents (no.) & Respondents (\%) \\
\hline 1 & 59 & 33.3 \\
2 & 42 & 23.7 \\
3 & 48 & 27.1 \\
4 & 16 & 9.0 \\
5 & 6 & 3.4 \\
6 & 3 & 1.7 \\
$0 /$ no theme represented & 3 & 1.7 \\
\hline
\end{tabular}

Table 3. Chi-square comparisons of themes identified for men and women in the study of understanding motivations for gardening.

\begin{tabular}{|c|c|c|c|}
\hline Theme & Gender & Respondents [no. (\%)] & $P$ \\
\hline \multirow[t]{2}{*}{ Therapeutic } & Male & $47(94.0)$ & 0.546 \\
\hline & Female & $115(91.3)$ & \\
\hline \multirow[t]{2}{*}{ Food/health/nutrition } & Male & $26(52.0)$ & $0.092^{*}$ \\
\hline & Female & $48(38.1)$ & \\
\hline \multirow[t]{2}{*}{ Social interactions } & Male & $8(16.0)$ & 0.723 \\
\hline & Female & $23(18.3)$ & \\
\hline \multirow[t]{2}{*}{ Aesthetics } & Male & $10(20.0)$ & 0.119 \\
\hline & Female & $40(31.7)$ & \\
\hline \multirow[t]{2}{*}{ Economics } & Male & $13(26.0)$ & 0.370 \\
\hline & Female & $25(19.8)$ & \\
\hline \multirow[t]{2}{*}{ Environmental benefits } & Male & $5(10.0)$ & 0.291 \\
\hline & Female & $7(5.6)$ & \\
\hline \multirow[t]{2}{*}{ Nostalgia } & Male & $1(8.0)$ & $0.085^{*}$ \\
\hline & Female & $3(2.4)$ & \\
\hline \multirow[t]{2}{*}{ Personal productivity } & Male & $3(6.0)$ & $0.063^{*}$ \\
\hline & Female & $21(16.7)$ & \\
\hline
\end{tabular}

* Statistically significant at $P \leq 0.10$ "all I'm good for." The third respondent mentioned a general appreciation for plants. On these responses, there was not a clear consensus on the classification among the researchers coding; therefore, they were not tallied and included within the analysis.

Gender. Frequency statistics indicated that males and females both cited therapeutic reasons for gardening most often (Table 3 ). A chi-square analysis was used to evaluate whether males and females provided different thematic responses at a statistically significant rate. Significant differences were found in the areas of food/health/nutrition with more males compared with females gardening for this reason $[P=0.092$ (Table 3)]. In research, an inverse relationship was established between an increased number of health practices in which both males and females participated and the lowest mortality rates for either. Women who reported gardening, among other exercise, had some of 
the lowest mortality rates (Belloc, 1973). Previous research has been inconclusive in indicating differences in fruit and vegetable consumption among male vs. female older adults (Baker and Wardle, 2003; Sommerfeld et al., 2010).

More males also gardened for reasons related to nostalgia $[P=$ 0.085 (Table 3)]. However, previous studies have found similar responses of males to females to emotional triggers regarding nostalgia (Batcho, 1995). In this study, females gardened more for personal productivity when compared with males $[P=$ 0.063 (Table 3)]. Past studies have indicated that women often have difficulty in devoting time toward leisure because they feel they need to earn the time spent in leisure activity (Henderson and Dialeschki, 1991). Perhaps, gardening is one outlet where they feel they can spend time and energy with no guilt because they reap a physical harvest or a wellmaintained landscape while pursuing the activity. However, the sampling difference between men and women with far fewer men represented in the data may be a limitation when drawing conclusions from these data and the study. With this limitation, the results of this study must be considered with additional research to confirm this finding.

Age. Chi-square analysis could not be used with IBM SPSS (version 20) for age group comparisons because expected cell counts were fewer than five in some instances (Bandyopadhyay, 2011). Therefore, Fisher's exact test was calculated using SAS (version 9.4) to understand the differences in thematic responses for different age groups. No statistically significant differences were identified between the age groups on the frequency of themes identified for gardening. This indicated that the reasons people garden were similar across various generations revealing the universality and meaningfulness of gardening in different stages of life. Previous research has found in directed studies toward youth or senior citizens that gardening appeals to gardeners of different ages (Koch et al., 2006; Sommerfeld et al., 2010; Waliczek et al., 2005). However, few have investigated different age groups all at once in an exploratory manner surmising reasons why gardeners choose to garden.

\section{Conclusions}

Results of the study showed that respondents gardened for similar reasons across various generations and supports previous research indicating gardens are meeting needs beyond producing food and flowers (Kaplan, 1973; Waliczek et al., 1996, 2005). This study expands beyond the benefits of gardening to identify motivations for participating in gardening activities. It is interesting that in some cases, the benefits and motivations are similar, but in others cases, the benefits are not the motivations. For example, the environment was infrequently mentioned as a motivation for gardening, despite the benefit of improved environmental attitudes and behaviors as a result of gardening (Aguilar et al., 2008).

It is interesting that therapeutic reasons for gardening were the most reported reasons. This differs for reasons people become Master Gardeners, for example, which appears to primarily be for learning (personal productivity) (Simonson and Pals, 1990; Schrock et al., 2000). It might be that people consider gardening and garden training differently and participate in the two activities for different reasons. This might indicate that Master Gardeners are a different population from gardeners who do not participate in the Master Gardener program and should be considered differently in quantitative research studies. Further research should be conducted to better understand the similarities and differences in Master Gardeners and gardeners who do not participate in the Master Gardener program.

The qualitative design of this study opened up the opportunity for newly identified reasons for gardening to emerge when compared with quantitative designs that presuppose researchers knowing possible reasons to include in survey questions. The new themes of personal productivity and nostalgia that emerged in this study regarding motivations to participate in gardening could be used by quantitative researchers and in producing directed horticultural marketing efforts, designing horticultural programs for particular groups, or both. For example, gardening programs targeting children could advertise the benefits of creating memories and improving personal productivity to the parents of children to get parents interested in enrolling their children. Programs targeting older adults could similarly address nostalgia and feeling productive as reasons why these individuals should participate, instead of the traditional health benefits which may feel overplayed and out-of-touch with this population of gardeners. In advertising other types of products, marketing efforts incorporating nostalgia have been successful (Schindler and Holbrook, 2003).

This study provides a rationale for further research to clarify gender differences in reasons for gardening, as differences found in gender comparisons could be used in marketing efforts of plant materials in particular venues where men vs. women are known to shop. However, because this study lacked representative distribution of genders, we caution against using the data from the present study alone for that purpose. Quantitative research could provide further support to understand the gendered differences in reasons for gardening, including the new themes identified in this study.

This study was limited in that it was based on self-reported data. Selfreported data are sometimes susceptible to bias of the participant and researcher (Fan et al., 2006). The demographic variables of ethnicity, income, education, and place of residence were not collected. In addition, some age group categories and males could have included more representation. This information would have allowed for more comparisons among demographics to be investigated, and a stronger study should be included in future studies.

\section{Literature cited}

Aguilar, O.M., T.M. Waliczek, and J.M. Zajicek. 2008. Growing environmental stewards: The overall effect of a school gardening program on environmental attitudes and environmental locus of control of different demographic groups of elementary school children. HortTechnology 18:243-249. 
Ashton-Shaeffer, C. and A. Constant. 2005. Why do older adults garden? Act. Adapt. Aging 30:1-18.

Baker, A.H. and J. Wardle. 2003. Sex differences in fruit and vegetable intake in older adults. Appetite 40:269-275.

Bandyopadhyay, D. 2011. Lecture 10: Partitioning chi square and residual analysis. 15 Jan. 2018. <http://people.musc. edu/ bandyopd/bmtry711.11/ lecture_10.pdf>.

Batcho, K. 1995. Nostalgia: A psychological perspective. Percept. Mot. Skills 80:131-143.

Behe, B., B. Campbell, C. Hall, H. Khachatryan, J. Dennis, and C. Yue. 2013. Consumer preferences for local and sustainable plant production characteristics. HortScience 48:200-208.

Behe, B.K., B. Campbell, J. Dennis, C. Hall, R. Lopez, and C. Yue. 2010. Gardening consumer segments vary in ecopractices. HortScience 45:1475-1479.

Belloc, N. 1973. Relationship of health practices and mortality. Prev. Med. 2:6781.

Bhatti, M. 2006. When I'm in the garden I can create my own paradise: Homes and gardens in later life. Sociol. Rev. 54:318341 .

Blair, D. 2009. The child in the garden: An evaluative review of the benefits of school gardening. J. Environ. Educ. 40:15-38.

Blair, D., C.C. Giesecke, and S. Sherman. 1991. A dietary, social, and economic evaluation of the Philadelphia urban gardening project. J. Nutr. Educ. 23:161167.

Blanchard, C.M., K.D. Stein, F. Baker, M. F. Dent, M.M. Denniston, K.S. Courneya, and E. Nehl. 2004. Association between current lifestyle behaviors and healthrelated quality of life in breast, colorectal, and prostate cancer survivors. Psychol. Health 19:1-13.

Boyer, R., T.M. Waliczek, and J.M. Zajicek. 2002. The Master Gardener program: Do benefits of the program go beyond improving the horticultural knowledge of participants? HortTechnology 12:432436.

Butterfield, B. 2009. The impact of home and community gardening in America. Natl. Gardening Assn., South Burlington, VT.

Carney, P.A., J. Hamada, R. Rdesinski, L. Sprager, K. Nichols, B. Liu, J. Pelayo, M.A. Sanchez, and J. Shannon. 2012. Impact of a community gardening project on vegetable intake, food security and family relationships: A community-based participatory research study. J. Community Health $37: 874$.

Centers for Disease Control and Prevention. 2007. Improving the health of older Americans: A CDC priority. Chronic Dis. Notes Rpt. 18:1-7.

Cicchetti, D.V. 1994. Guidelines, criteria, and rules of thumb for evaluating normed and standardized assessment instruments in psychol. Psychol. Assess. 6:284-290.

CoDyre, M., E. Fraser, and K. Landman. 2015. How does your garden grow? An empirical evaluation of the costs and potential of urban gardening. Urban For. Urban Green. 14:72-79.

Devine, C.M., W.S. Wolfe, E.A. Frongillo, and C.A. Bisogni. 1999. Life-course events and experiences: Association with fruit and vegetable consumption in 3 ethnic groups. J. Amer. Dietetic Assn. 99:309-314.

Everard, K.M., H.W. Lach, E.B. Fisher, and M.C. Baum. 2000. Relationship of activity and social support to the functional health of older adults. J. Gerontol. B Psychol. Sci. Soc. Sci. 55:208-212.

Fan, X., B. Miller, K. Park, B. Winward, M. Christensen, H. Grotevant, and R. Tai. 2006. An exploratory study about inaccuracy and invalidity in adolescent self-report surveys. Field Methods 18:223244.

Gutek, G. 2004. The Montessori method: The origins of an educational innovation: Including an abridged and annotated edition of Maria Montessori's the Montessori method. Rowman and Littlefield, Lanham, MD.

Hale, J., C. Knapp, L. Bardwell, M. Buchenau, J. Marshall, F. Sancar, and J. Litt. 2011. Connecting food environments and health through the relational nature of aesthetics: Gaining insight through the community gardening experience. Soc. Sci. Med. 72:1853-1863.

Hawkins, G., S.E. Burnett, and L.B. Stack. 2012. Survey of consumer interest in organic, sustainable, and local container-grown plants in Maine. HortTechnology 22:817-825.

Henderson, K. and M.D. Dialeschki. 1991. A sense of entitlement to leisure as constraint and empowerment for women. Leis. Sci. 13:51-65.

Infantino, M. 2004. Gardening: A strategy for health promotion in older women. J. N. Y. Nurses Assn. 35:10-17.

Kaplan, S. 1973. Cognitive maps, human needs and the designed environment, $\mathrm{p}$. 275-283. In: W.F.E. Preiser (ed.). Envi- ronmental design research. Dowden, Hutchinson and Ross, Stroudsburg, PA.

Kaplan, S. 1992. The restorative environment: Nature and human experience, p. 134-142. In: D. Relf (ed.). The role of horticulture in human well-being and social development. Timber Press, Portland, OR.

Kelley, R., T.M. Waliczek, and F.A. Le Duc. 2017. The effects of greenhouse activities on psychol. stress, depression, and anxiety among university students who served in the U.S. armed forces. HortScience 52:1834-1839.

Kidd, J.L. and W. Brascamp. 2004. Benefits of gardening to the well-being of New Zealand gardeners. Acta Hort. 639:103-112.

Koch, S., T.M. Waliczek, and J.M. Zajicek. 2006. The effect of a summer garden program on the nutritional knowledge, attitudes and behaviors of children. HortTechnology 16:620-624.

Mast, G. 2013. The geography of motivation and participation among community gardeners in Austin, Texas. Texas State Univ., San Marcos, TX, Thesis.

Noymer, A. 2008. Alpha, significance level of test, p. 17-19. In: P.J. Lavrakas (ed.) Encyclopedia of survey research methods. Sage Publ., Thousand Oaks, CA.

Park, S., K. Lee, and K. Son. 2011. Determining exercise intensities of gardening tasks as a physical activity using metabolic equivalents in older adults. HortScience 46:1706-1710.

Pigg, A., T.M. Waliczek, and J.M. Zajicek. 2006. The effect of a school gardening program on the math and science achievement of elementary students. HortTechnology 16:262-264.

Relf, D. 1998. People-plant relationships, p. 21-42. In: S.P. Simpson and M.C. Straus (eds.). Horticulture as therapy. Food Products Press, New York, NY.

Relf, D. and S. Dorn. 1995. Horticulture: Meeting the needs of special populations. HortTechnology 5:94-103.

Schindler, R. and M. Holbrook. 2003. Nostalgia for early experience as a determinant of consumer preferences. Psychol. Mktg. 20:275-302.

Schrock, D.S., M. Meyer, P. Ascher, and M. Snyder. 2000. Reasons for becoming involved as a Master Gardener. HortTechnology 10:626-630.

Shrout, P. and J. Fleiss. 1979. Intraclass correlations: Uses in assessing rater reliability. Psychol. Bull. 86:420-428. 
Simonson, D.L. and D.A. Pals. 1990. Master Gardeners: Views from the cabbage patch. J. Ext. 28(2):2RIB3. 19 Mar. 2018. <https://www.joe.org/joe/ 1990summer/rb3.php>.

Sommerfeld, A., A.L. McFarland, T.M. Waliczek, and J.M. Zajicek. 2010. Growing minds: Evaluating the relationship between gardening and fruit and vegetable consumption in older adults. HortTechnology 20:711-717.
Thomas, D.R. 2006. A general inductive approach for analyzing qualitative evaluation data. Amer. J. Eval. 27:237-246.

Waliczek, T.M., R.H. Mattson, and J.M. Zajicek. 1996. Benefits of community gardening on quality of life issues. J. Environ. Hort. 14:204-209.

Waliczek, T.M., J.M. Zajicek, and R.D. Lineberger. 2005. The influence of gardening activities on consumer perceptions of life. HortScience 40:1360-1365.
Webber, C.B. and A. Rojhani. 2010. Food or fuel. Rising gasoline prices and food access among WIC families in nonmetropolitan southwest Michigan. J. Hunger Environ. Nutr. 5:484-497.

Yusuf, H.R., J.B. Croft, W.H. Giles, R.F. Anda, M.L. Casper, C.J. Caspersen, and D.A. Jones. 1996. Leisure-time physical activity among older adults United States, 1990. Arch. Intern. Med. 156:13211326. 